Rakenteiden Mekaniikka (Journal of Structural Mechanics)

Vol. 51, No 1, 2018, pp. 10-26

http://rakenteidenmekaniikka.journal.fi/index

https:/doi.org/10.23998/rm.69036

(C)Author(s) 2018.

Open access under CC BY-SA 4.0 license.

\title{
Experimental study of the dynamic indentation damage in thermally shocked granite
}

\author{
Ahmad Mardoukhi ${ }^{1}$, Mikko Hokka and Veli-Tapani Kuokkala
}

\begin{abstract}
Summary. This paper presents an experimental procedure to study the effects of pre-existing cracks and damage on the rock behavior under dynamic indentation. To gain better understanding on the mechanism involved in percussive-rotary drilling procedure, a modified Split Hopkinson Pressure Bar device was used to carry out dynamic indentation tests, where rock drill buttons were impacted on rock samples with dimensions of $30 \mathrm{~cm} \times 30 \mathrm{~cm} \times 30 \mathrm{~cm}$. Before the mechanical testing, the samples were thermally shocked using a plasma spray gun for periods of 3,4 , and 6 seconds. The plasma gun produces a powerful heat shocks on the rock sample, and even short exposures can change the surface structure of the samples and provide samples with different crack patterns and surface roughness for experimental testing. The effects of the heat shock damage on the dynamic indentation behavior of the rock were characterized with singleand triple-button indentation tests. The specific destruction work was used to characterize the effects of heat shocks on the material removal during dynamic indentation. The results show that the force-displacement response of the rock does not change much even if the rock surface is severely damaged by the heat shock, however, the destruction work decreases significantly. This means that the same loading removes more volume if the material surface is pre-damaged, and that the efficiency of the indentation process cannot be evaluated from the bit-rock interaction forces alone. The presented experimental framework can be a useful tool for the verification of numerical models where the rock microstructure and especially the microcracks are essential.
\end{abstract}

Key words: granite, heat shock, dynamic indentation, indentation damage, destruction work

Received 15 January 2018. Accepted 28 April 2018. Published online 16 August 2018.

\section{Introduction}

Rotary-percussive drilling is widely used in tunnel excavation, shallow well boring, and mining industry. The method has applications also in oil and gas drilling in the areas where hard igneous rocks such as granite are found. The basic mechanism of rotarypercussive drilling is the repetition of impacts of the drill hammer on the rock mass in addition to the rotation of the drill. The efficiency of the method, however, depends on various properties of the rock including the brittleness and strength. The more brittle the

${ }^{1}$ Corresponding author: ahmad.mardoukhi@tut.fi 
rock is, the more favorable the creation of radial cracks and side chipping become during the process $[1,23]$. The brittleness of the rock material can vary according to the drilling conditions. For instance, while drilling for geothermal energy, the depth of the wells can reach 5000 meters. At this depth, the confining pressure and temperature of the rock increase $[3,7,22]$. Usually at these conditions, the rock shows less brittle or even somewhat ductile behavior while its strength increases significantly.

During percussive drilling, the rock is first deformed elastically, which is followed by the crushing of the surface asperities. In the third stage, the crushed zone begins to form under the indenter and finally the chips start to form along curved trajectories. The formation of the crushed volume and the side cracks are acknowledged as two essential phenomena of the fracturing process $[4,10,16,21]$ and therefore have a strong influence on the formation of the craters and the overall rate of penetration. The formation of the craters in the rocks has been studied extensively in the past [16, 21]. Maurer and Rinehart [16] studied the shape of the craters caused by an impact in sandstone and granite at different angles of impact. In sandstone, an impact at an angle of $90^{\circ}$ makes the projectile penetrate into the sample crushing the material in front of it. The crushed material is forced aside by the penetrator, which leads to the creation of a cylindrical hole. This cylindrical hole is surrounded by a zone of compressed material. In the upper part of the crater, side chipping takes place and causes the formation of a cup-shaped crater. The situation is a bit different when the projectile impacts the surface of granite. In this case, the crater has a small sloping side and no cylindrical hole is observed. Instead, the craters in granite have a cup shape. The authors [16] also stated that as the projectile penetrates into the material, the fracture occurs in a stepwise manner propagating along a logarithmic spiral. Finally, the authors reported that the penetration of the projectile is directly proportional to its mass and the difference between the impact speed and the minimum speed at which cratering occurs.

The complexity of chip formation and material removal during the indentation process makes the comprehensive experimental research of the rock behavior quite an overwhelming task, and therefore various modeling approaches are being developed. On the other hand, it is also quite difficult to establish a solid relationship between the existing cracks and their distributions and the strength and fragmentation of the rock, partly because rock samples with controlled crack sizes for mechanical testing are not easy to produce. Because of this, obtaining reliable experimental results to be used as input values for the numerical simulations and for model verifications can be quite challenging. Some preliminary work has been carried out by Saksala [17] who modeled the rock fracture under dynamic loading using a combined continuum damage embedded discontinuity model in the finite element method. Wang et al. [21] carried out simulations of the rock fragmentation process with two drill bits subjected to impact loading. The authors stated that in this loading condition the results show the appearance of radial cracks, incipient chips, pulverized zones, and shell cracks. They also concluded that the dynamic pressure plays an important role in the failure of the sample when using two indenters. The authors showed that in a homogeneous rock, a smooth tensile crack from the loading face propagates through the sample. However, in a heterogeneous rock, the fracture usually propagates along a curvilinear path during the failure. Heterogeneous rocks absorb more energy due to the imperfections in their structure, which leads to the severe absorption of the compressive stress waves by the rock. Due to the severe 
attenuation of the compressive waves in heterogeneous rocks, the reflected tensile stress waves are also weaker. Liu et al. [11] simulated the fragmentation of rock using single and double indenters. The authors reported that the rock deforms elastically at the initial loading stage. Later on, the tensile cracks are initiated around the corners of the indenter and propagate in a conical Hertzian manner. Further loading of the rock leads to the appearance of the crushed zones. Due to the appearance of the crushed zones, new tensile cracks start to propagate towards the surface and cause side chipping. Use of two indenters leads to the side chipping of the rock between the indenters. The spacing between the indenters is an important factor and affects the fragmentation efficiency. Despite all the previous efforts, there is still a gap in the understanding of the rock behavior in dynamic indentation loading conditions, as the usual force-displacement curves do not explain the process fully. In addition, the role of pre-existing cracks has not been examined thoroughly. The pre-existing cracks are an important feature of the material removal process in percussive drilling, as every impact causes damage and cracks to the material, which facilitates the material removal during the next and consecutive impacts.

As one can see, there are many factors and parameters affecting the rock behavior in a dynamic indentation test. Therefore, simplified versions of the dynamic indentation tests are used in the laboratory scale to gain understanding of the different affecting factors. The triple-button indentation tests are a simplification of in-situ drilling, but the laboratory environment allows a more careful evaluation of the results. In most cases, the scientists and engineers are interested in the overall drilling rate or the rate of penetration. Identification of different rock properties based on the bit-rock interaction forces would be very beneficial in drilling and mining, where the penetration through a rock layer could be detected from simple strain gage measurements. This could be used for example to identify the end of a pay layer. However, based on this work the bit-rock interaction forces are quite insensitive to small changes in the rock strength, and the effects of the preexisting damage and rock strength are more clearly seen in the removed volume and especially in the side chipping and material removal from between the buttons.

In addition to the factors mentioned above, the temperature plays an important role on rocks' mechanical response as well. The behavior of rock at high temperatures has been studied extensively. Decrease in the tensile strength of rock by increasing temperature has been reported by several researchers [5, 12]. Mahanta et al. [13] studied the effect of temperature on the mode I fracture toughness of three different Indian rocks. The results show that by increasing the temperature up to $100{ }^{\circ} \mathrm{C}$, the fracture toughness of all three rocks increases considerably. Beyond this point, the fracture toughness shows a decreasing trend as the temperature was increases up to $600{ }^{\circ} \mathrm{C}$. Bauer and Johnson [4] showed that the thermal expansion of quartz and feldspar play an important role in initiation and propagation of thermal cracks which is the main reason for weakening the rock at higher temperatures. Sirdesai et al. [19] concluded that the main reason for the changes in rock's characteristics upon heating is due to the minerals expansion. The change in the pores and micro-fracturing caused by the thermal expansion, leads to the alteration of rock's tensile strength.

The aim of the work is to develop an experimental procedure to facilitate future modeling efforts, and to quantify the effects of pre-existing cracks on the material removal during dynamic indentation. The heat shock method shows a good level of 
consistency in generating different crack patterns $[14,15]$, which enables experimental testing of the same rock type with different amounts of pre-existing damage. Therefore, it becomes easier to study and analyze the effects and the role of the pre-existing cracks on the dynamic indentation behavior and especially on the material removal of rock materials. The effects of different surface crack patterns on the material removal are studied using a modified Hopkinson Pressure Bar device, where one or three drill buttons are embedded into the impact-end of the incident bar.

\section{Experimental Procedure}

The material used in this work is Kuru Grey granite. Table 1 shows the chemical composition of the tested material. Kuru Grey has the mean value of open porosity of $0.44 \%$ and the quasi-static compression strength of about $220 \mathrm{MPa}$. The microstructure of the tested rock shows no evident texture. The minerals are also distributed homogenously and the mechanical properties are essentially isotropic.

Table 1. Mineral composition of Kuru Grey granite [6].

\begin{tabular}{cc}
\hline $\begin{array}{c}\text { Mineral } \\
\text { composition }\end{array}$ & Wt.\% \\
\hline Quartz & 35 \\
Albite & 31 \\
Microcline maxi & 28 \\
Biotite & 3 \\
Diopside & 2 \\
Chlorite IIb & 1 \\
\hline
\end{tabular}

Bulk samples of Kuru Grey with dimensions of $30 \mathrm{~cm} \times 30 \mathrm{~cm} \times 30 \mathrm{~cm}$ were used for the dynamic indentation tests. The heat shocks were applied by a $50 \mathrm{~kW}$ plasma gun, which was moved over the sample surface at a fixed distance at the speeds of $100 \mathrm{~mm} / \mathrm{s}$, $75 \mathrm{~mm} / \mathrm{s}$, and $50 \mathrm{~mm} / \mathrm{s}$ producing the shock duration of 3 seconds, 4 seconds, and 6 seconds, respectively. The temperature of the rock surface after the heat shock was $76^{\circ} \mathrm{C}$, $88^{\circ} \mathrm{C}$, and $100^{\circ} \mathrm{C}$ for the $3 \mathrm{~s}, 4 \mathrm{~s}$, and $6 \mathrm{~s}$ thermal shocks, respectively. For more details about the heat shock procedure, the readers are referred to Refs. [14, 15].

The indentation tests were carried out using single- and triple-button tungsten carbide indenters with the hemispherical geometry shown in Figure 1. The experimental setup is a Split Hopkinson Pressure Bar (SHPB) without the transmitted bar. The drill buttons were embedded in the impact end of the incident bar. The experimental setup is shown in Figure 2. The readers are referred to Refs. $[2,18]$ for more technical details and examples of tests carried out at different speeds, etc. 


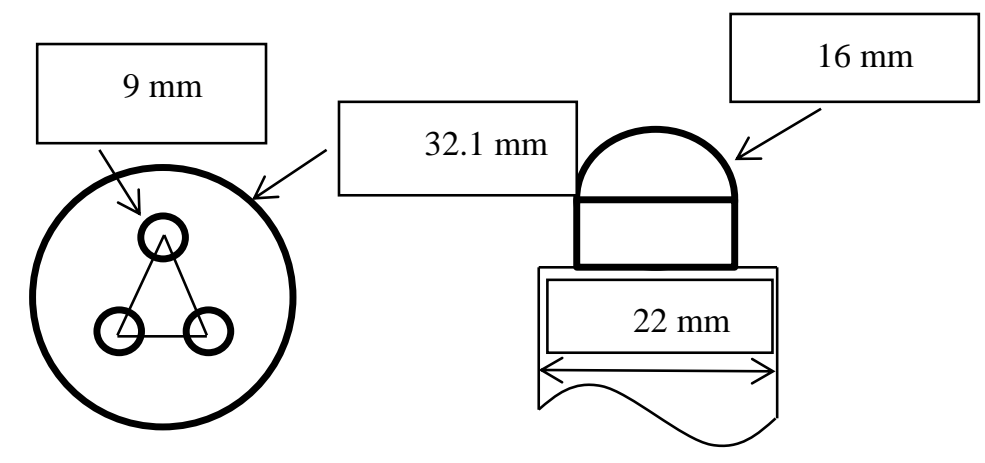

Figure 1. The triple-button and single button-bits.
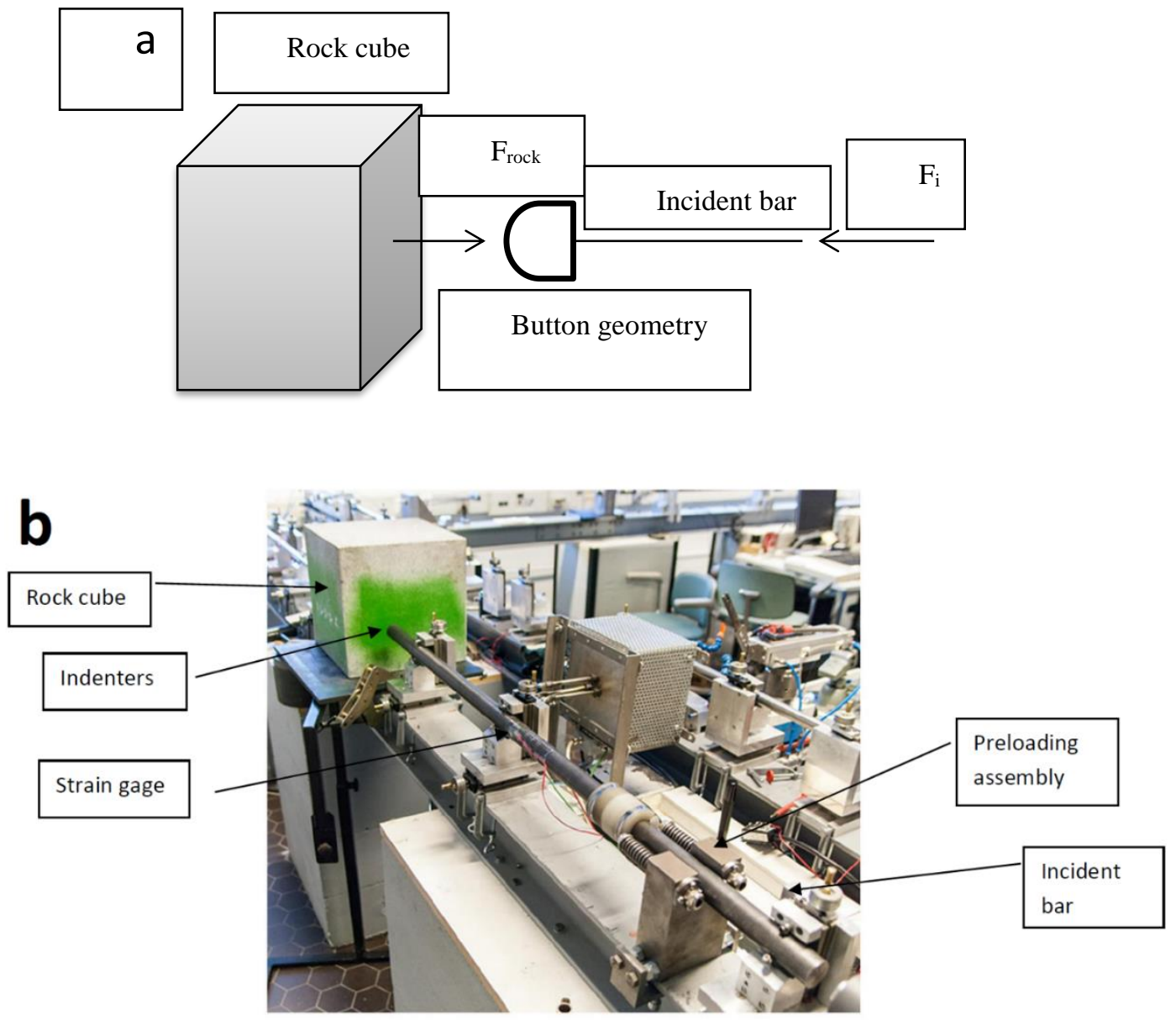

Figure 2. a) Schematic picture of the dynamic indentation test and b) the experimental setup.

The setup includes an air gun, a striker bar with the length of $20 \mathrm{~cm}$, and an incident bar with the length of $120 \mathrm{~cm}$ and a diameter of $22 \mathrm{~mm}$ made of AISI 4340 steel for the single-button tests. In the triple-button tests, the incident bar had a diameter of $32.1 \mathrm{~mm}$. The stress pulses were measured using two strain gages bonded on the surface of the 
incident bar at the center of the bar. The force on the bar-rock interface was calculated using the following equation:

$$
F(t)=A_{b} E_{b}\left(\varepsilon_{i}(t)+\varepsilon_{r}(t)\right)
$$

where $A_{b}$ is the cross sectional area of the incident bar, $E_{b}$ is the Young's modulus of the bar material, and $\varepsilon_{\mathrm{i}}$ and $\varepsilon_{\mathrm{r}}$ are the measured and dispersion corrected incident and reflected strains as a function of time. The numerical dispersion correction method used in this work was adopted from the original work of Gorham [7]. Two springs were used to apply a small force $(40 \pm 2 \mathrm{~N})$ to push the incident bar towards the rock to secure a sufficient initial contact between the bits and the rock. In addition, the quality of the contact between the rock and the buttons was verified before each test with a sheet of white paper and a carbon paper between the rock and the indenters. If the contact was not even, the alignment of the rock and the bar was adjusted accordingly. Examples and more details of the alignment of the triple-button bit can be found in Ref. [18].

The single-button tests were conducted at the impact speed of $19 \mathrm{~m} / \mathrm{s}$. In these tests the diameter of the striker and the incident bars were the same, and therefore the impact speed of the indenter on the rock is also close to the impact speed of the striker. However, the triple-button tests were carried out with an incident bar with a larger diameter than the striker bar. Therefore, the triple-button tests needed a higher striker speed to compensate for the difference in the cross section. When the cross sectional areas of the incident bar and the striker are the same, the relationship between the striker speed and the stress in the incident bar can be evaluated using equation (2):

$$
V_{s}=\frac{2 \sigma_{\text {bar }}}{\rho C}=\frac{2 \sigma_{\text {striker }}}{\rho C}
$$

where $\rho$ is the density and $\mathrm{C}$ the speed of sound of the bar material. Equation (2) can also be used to evaluate the striker speed in the triple-button test that will result in the same indentation speed as in the single indentation test. Based on this, a striker speed of $41 \mathrm{~m} / \mathrm{s}$ would be required in the triple-button tests, but due to the technical limitations of the device, the maximum striker speed of $35 \mathrm{~m} / \mathrm{s}$ was used instead.

The craters produced by the indenter(s) were replicated using a commercial NDT quality resin. These replicas were analyzed using Alicona Infinite Focus G5 optical profilometer. The 3D images obtained from the profilometry were processed using IFMeasureSuite software to measure the volume of the craters for the calculation of the destruction work.

\section{Result and Discussion}

Figures 3 a-d show the force vs. displacement curves for the single-button tests for the non-heat shocked surface as well as for the $3 \mathrm{~s}, 4 \mathrm{~s}$, and $6 \mathrm{~s}$ heat shocked surfaces. As can be seen from these Figures, for all samples the depth of penetration is almost the same with the same level of applied force. Another important feature in these curves is the appearance of a second maximum. The most likely explanation for the shape of the forcedisplacement curve is that the bit first damages the rock surface severely and then continues to move inwards, trapping the produced powder between the crater surfaces 
and the bit. Further forward movement of the bit leads to the compaction of the powder, which manifests itself as the second maximum. Therefore, a part of the force applied on the rock is consumed on compacting the powder under the bit instead of causing further damage to the rock. The force-displacement curves do not resemble the typical experimental bit-rock interaction curves, where elastic recovery is often observed. However, it has been shown [18] that the behavior of the rock and the bit-rock interaction for this rock change at higher speeds, where elastic recovery is not observed as the material is shattered into dust in front of the indenter.
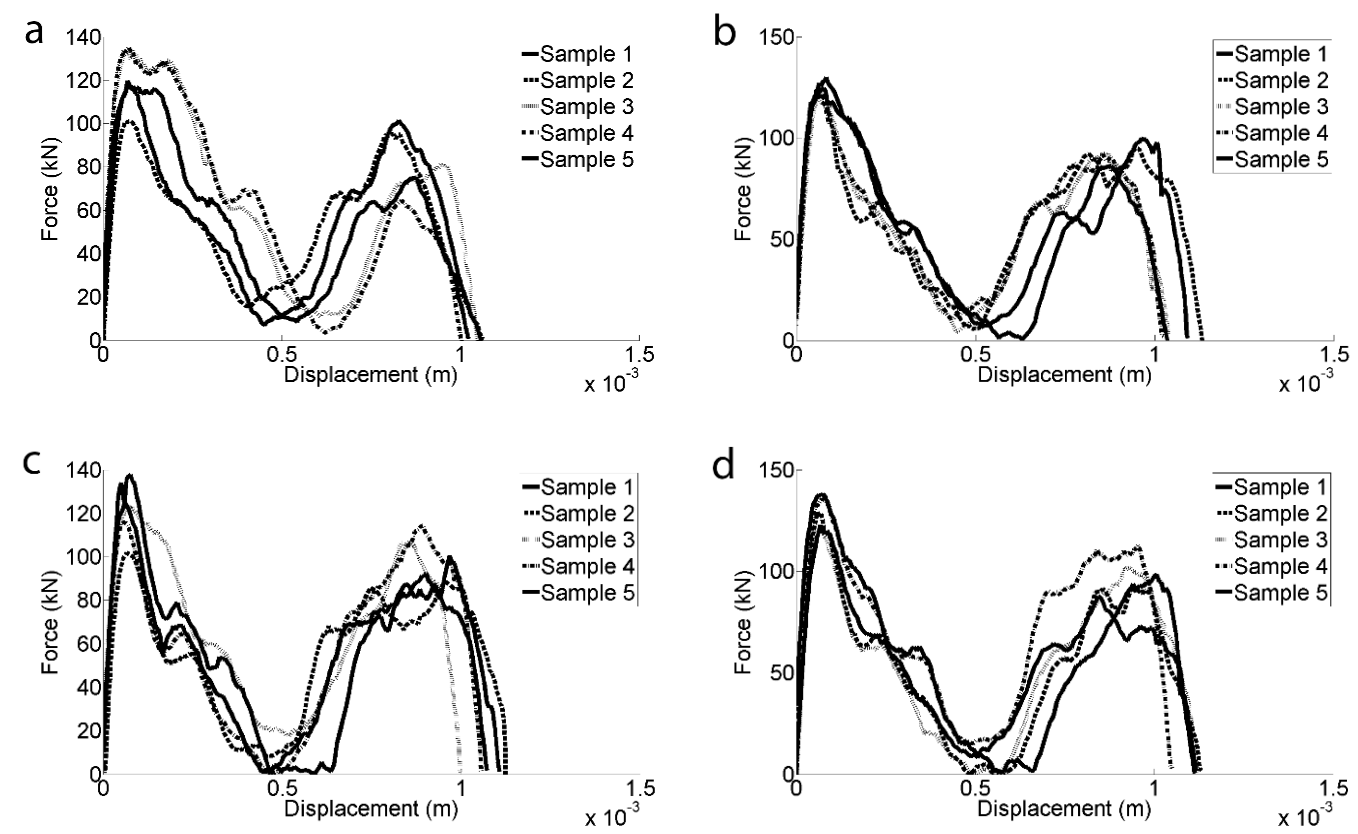

Figure 3. Force vs. displacement curves for a) non-heat shocked surface, b) $3 \mathrm{~s}$ heat shocked surface, c) $4 \mathrm{~s}$ heat shocked surface, and d) $6 \mathrm{~s}$ heat shocked surface.

The force-displacement curves give an impression that the heat shocks have no effect on the rock behavior. However, the force-displacement curves do not provide information about the volume of the crater. As the rock has been weakened by the heat shock, the indenter removes material in the direction of the applied force, but also the side chipping increases significantly, which is evidently not observable in the force-displacement data. The profilometry results indicate that the volume of the craters increases with the duration of the heat shock. As an example, Figure 4 shows the crater formed during the dynamic indentation process on the samples heat shocked for 3 and 6 seconds, and the height profile of the craters. 

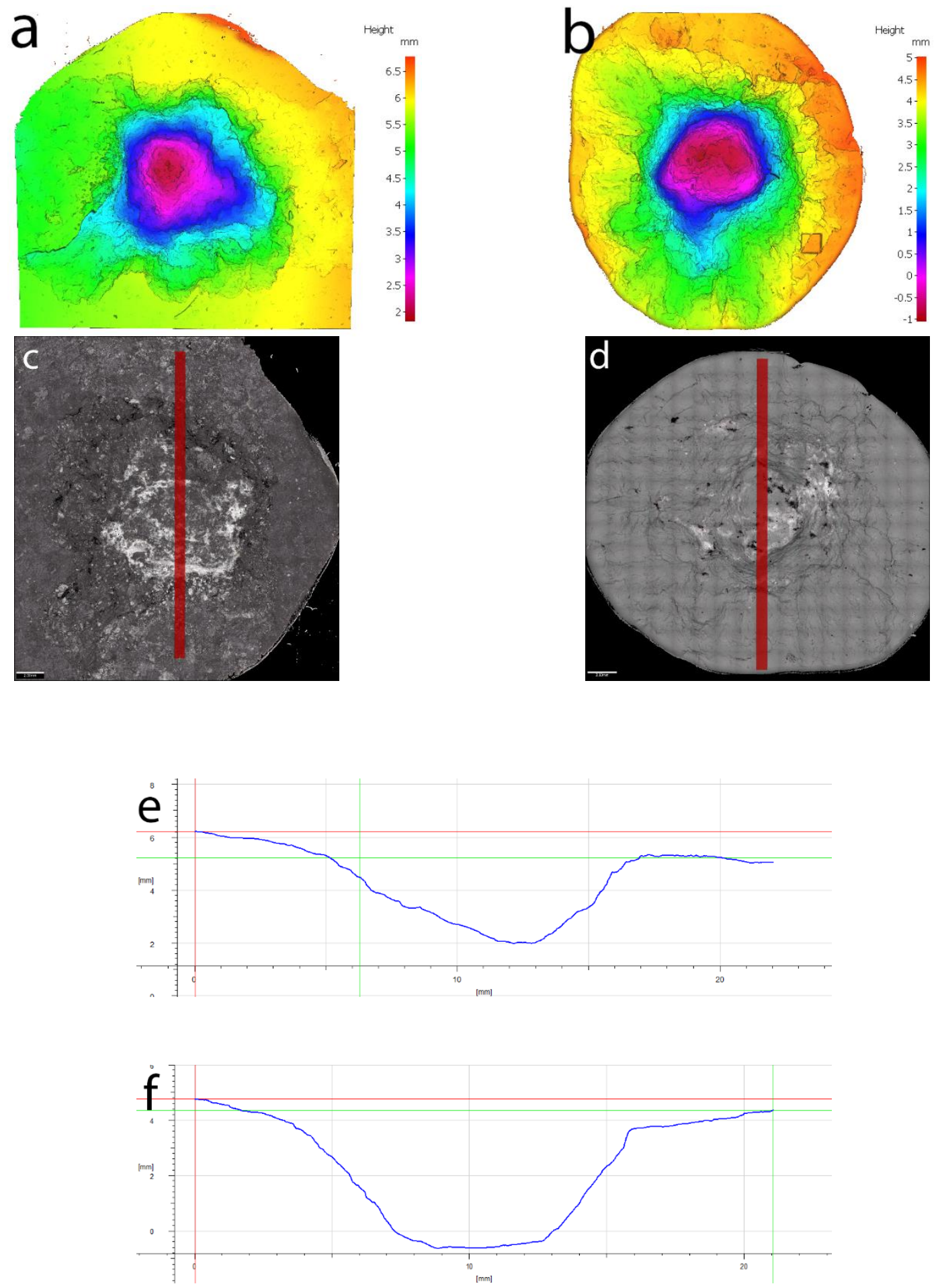

Figure 4. 3D profilometer images of the crater formed during an indentation on a a) 3 second heat shocked surface, perpendicular view of the mapped image, b) 6 second heat shocked surface, perpendicular view of the mapped image, c) 3 second heat shocked surface, perpendicular view of the raw image with the profile line, d) 6 second heat shocked surface, perpendicular view of the raw image with the profile line, e) height profile of the crater for a 3 second heat shock surface, and f) height profile of the crater for a 6 second heat shock surface. 
Table 2 summarizes the data obtained from the crater volume measurements. It is evident that by increasing the duration of the thermal shock, the volume of the crater increases as well. This increase is $14 \%, 66 \%$, and $77 \%$ for the $3 \mathrm{~s}, 4 \mathrm{~s}$, and $6 \mathrm{~s}$ heat shocks, respectively. However, it is worth mentioning that the dynamic indentation tests described in this work are not single indentation tests, as the rock is impacted several times by the stress pulses reflecting back-and-forth in the incident bar. The forcedisplacement curves depicted in Figure 3 show only the first impact, whereas the volume of the crater is a result of all impacts. Nevertheless, the first impact causes the main damage and the rest of the impacts are mostly compacting the dust beneath the indenter, and therefore the error remains manageable.

Table 2. Volume of the craters caused by the dynamic indentation of non-heat shocked and heat shocked surfaces $\left(\mathrm{mm}^{3}\right)$.

\begin{tabular}{ccccc}
\hline & $0 \mathrm{~s}$ & $3 \mathrm{~s}$ & $4 \mathrm{~s}$ & $6 \mathrm{~s}$ \\
\hline & 197.14 & 291.33 & 301.77 & 285.61 \\
& 202.63 & 261.56 & 305.1 & 329.69 \\
& 200.3 & 277.72 & 381.88 & 375.4 \\
& 188.35 & 227.15 & 399 & 449.52 \\
& 196.12 & 226.66 & 254.43 & 391.79 \\
\hline Average & 196.91 & 256.88 & 316.43 & 366.4 \\
\hline STDEV & 5.435 & 29.32 & 47.39 & 62.27 \\
\hline
\end{tabular}

Knowing both the volume of the crater and the work done by the indenter, i.e., the area under the force-displacement curve, allows the calculation of the destruction work $\left(\mathrm{W}_{\mathrm{z}}\right)$ for each indentation. The concept of destruction work was first introduced by Thuro and Spaun [20], and it describes the amount of mechanical work that is needed to remove a unit volume from the surface of the rock. The force-displacement curves at this impact speed show consistently a second maximum, as described and explained earlier, and the destruction work was calculated separately for the first part of the force-displacement curve covering the first peak and half of the following valley, and for the entire measured force-displacement data. The former is from here on called the primary specific destruction work and the latter the total specific destruction work.

Figure 5 shows the specific destruction work obtained from the single-button tests. As can be seen from the graph, the destruction work decreases as the duration of the heat shock increases. This is expected even though it is not evident from the forcedisplacement data. The destruction work decreases faster when the duration of the heat shock increases to four seconds. The reduction of the total destruction work compared to the non-heat shock tests is about $6 \%, 20 \%$, and $30 \%$ for $3 \mathrm{~s}, 4 \mathrm{~s}$ and $6 \mathrm{~s}$ heat shocks, respectively. The decrease in the specific destruction work becomes less pronounced after a certain duration of the heat shock (between 4 and $6 \mathrm{~s}$ heat shocks). One possible explanation for this observation is that the damage on the sample surface during a foursecond heat shock is already so severe that adding more damage will not facilitate additional material removal. Another possible explanation is that heat shocks longer than four seconds do not add more cracks and damage to the surface, and that the more damaged material is always removed from the surface by the plasma spray. 


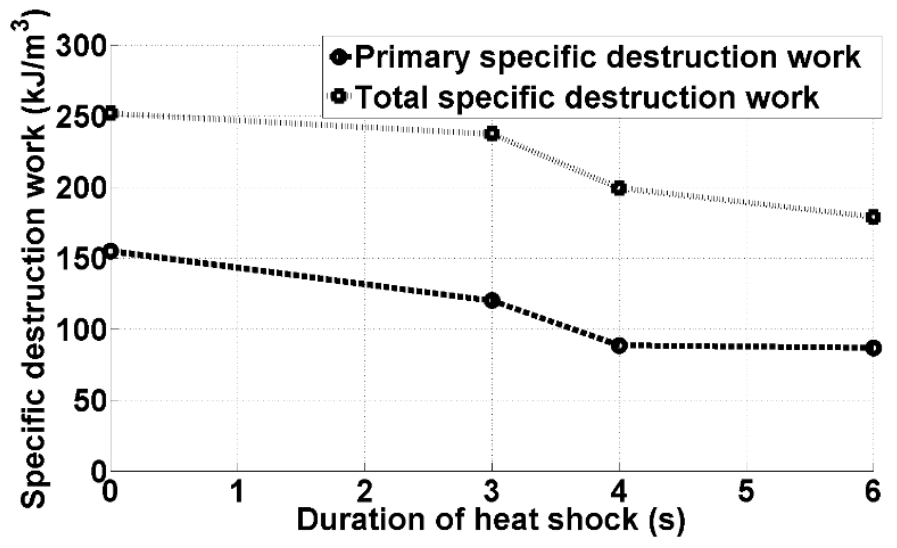

Figure 5. Specific destruction work for the first peak (primary) and for the full force-displacement curve (total) obtained from the single-button indentation test.

Figure 6 shows the force-displacement curves obtained from the triple-button indentation tests. The shapes of the curves are significantly different from those observed in the single-button tests, and a clear second maximum is not observed in any of the plots. However, the force-displacement curves for the $3 \mathrm{~s}$ and $4 \mathrm{~s}$ heat shocks (Figures $6 \mathrm{~b}$ and 6c) have a somewhat similar shape where an intermediate drop in the bit-rock interaction force is observed before a gradual increase towards the end of the test. The reason for the difference between the single-button and triple-button bit-rock interaction forces is that the indenters used in the triple-button tests are considerably smaller than the button used in the single-button tests. Therefore, the amount of dust and powder, which is trapped under the indenter is smaller. Additionally, as the area between the indenters is damaged and material is removed also from that area, it provides the space for the produced dust and powder to leave the craters. However, it should be noted this reasoning is at best speculative and additional studies and tests such as recovery system test or stress reversal test should be carried out to confirm the hypothesis.

The bit-rock interaction force for the rock without a heat shock is essentially the same as for the rock with a 3 second heat shock. The data is consistent and the scatter is rather low. However, the indenter seems to penetrate slightly deeper into the rock with some pre-existing heat shock damage. When the duration of the heat shock increases to 4 seconds, the force levels remain unchanged and the scatter increases only slightly compared to the scatter in the tests with the intact rock. However, the scatter increases considerably in the results obtained for the rock with a 6 second heat shock. The increased scatter is most likely due to an increase in the side chipping. As the duration of the heat shock increases, the damaged area and volume in the specimen increases as well. This damage can facilitate the side chipping of the rock material during the indentation process. As mentioned before, a typical force-displacement curve tends to move backward at the end of the test. However, this behavior is not observed in the forcedisplacement curves obtained in this work. Instead, a sharp drop at the end of the tests can be seen, indicating the end of the forward movement of the incident bar, i.e., the end of the test. 

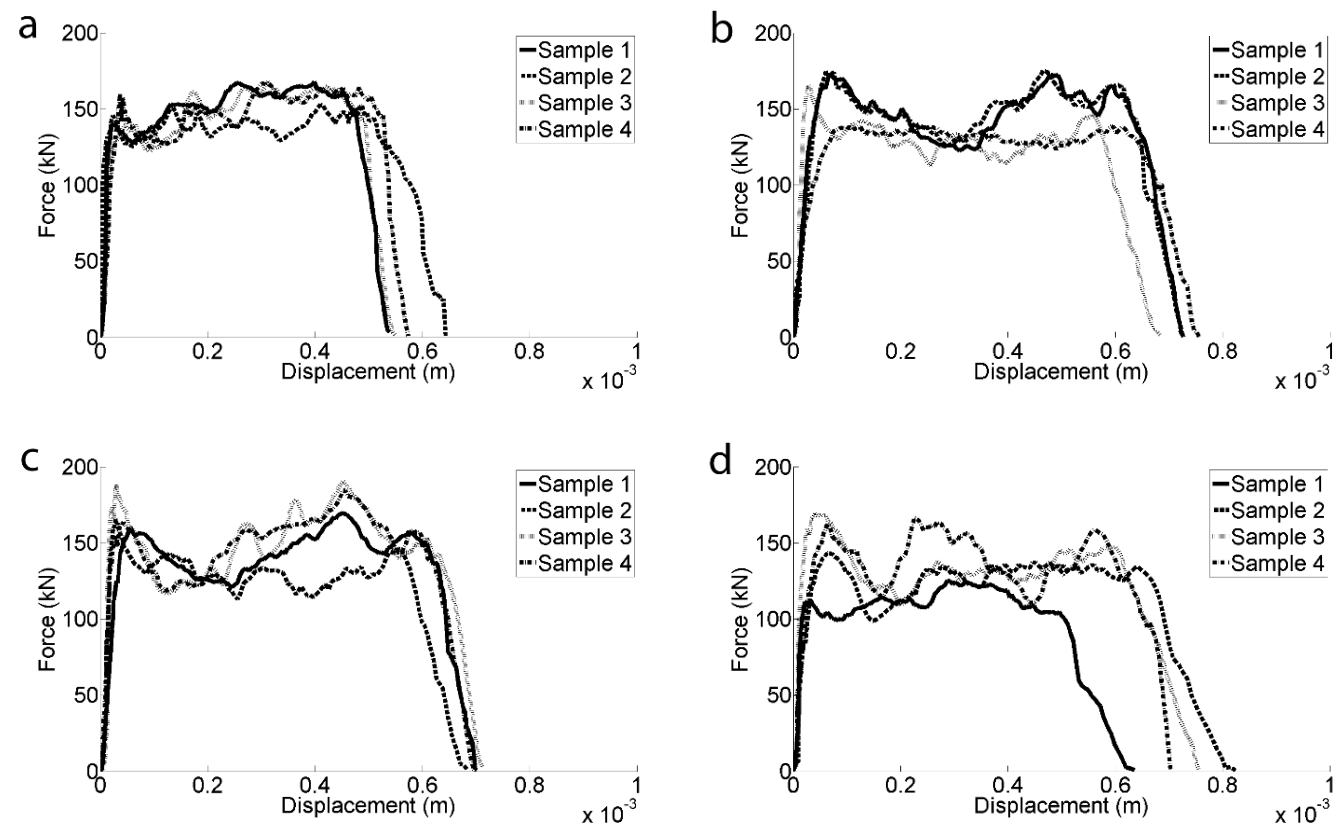

Figure 6. Force vs displacement data for a) non-heat shocked surface, b) $3 \mathrm{~s}$ heat shocked surface, c) $4 \mathrm{~s}$ heat shocked surface, and d) $6 \mathrm{~s}$ heat shocked surface.

A typical force-displacement curve reaches a maximum and then turns back towards smaller displacement values, indicating unloading of the sample. The unloading phase, however, is not observed in the single-button nor in the triple-button test results of this work. On the other hand, Saksala et al. [18] have observed that as the impact velocity increases, the curves start to lose their typical shape and the unloading part eventually starts to disappear. Another possible explanation for the observed behavior in the singlebit indentation tests could be that a shock wave front is formed just under the indenter tip crushing the rock in front of the bit faster than the bit penetrates, hence the drop in force along with increasing penetration is observed. Then, when the shock conditions are not fulfilled anymore, the rock starts to resist the penetration resulting in the observed second peak in force. The reason why this does not take place in the triple-button test is that the total force is divided into three parts for three buttons. Figure 7 shows the damaged area during the dynamic indentation and Figure 8 the craters, which were analyzed using optical profilometry with the height profile to clarify the increase of the volume of the crater as the duration of the heat shock increases

The destruction work was calculated in the same manner for the triple-button tests as described for the single-button tests. Figure 9 shows the specific destruction work for the triple-button tests and the depth of the crater caused by the impact. As it is evident, larger heat shock damage leads to lower specific destruction work. The decrease in the specific destruction work of the heat-shocked samples compared to the non-heat shock tests is about $3 \%, 11 \%$, and $30 \%$ for $3 \mathrm{~s}, 4 \mathrm{~s}$, and $6 \mathrm{~s}$ heat shock, respectively. The forcedisplacement curves for the triple-button tests are quite similar for all tests including the non-heat shocked and the heat-shocked surfaces. Therefore, the mechanical energy consumed in the tests varies only little. However, the volume of the craters becomes larger with increasing heat shock damage, which is seen as lower destruction work. The drop in 
the destruction work is not significant for the $3 \mathrm{~s}$ heat shock, but already at $4 \mathrm{~s}$ the drop becomes significant. Also the depth of the crater increases with increasing pre-existing heat shock damage. However, the total damaged volume increases much faster than the depth of the crater because of the increasing side chipping and the removal of the material in between the buttons.

The amount of material removed outside the contact area between the buttons and the rock is actually very important, and it has a strong effect on the overall rate of penetration in drilling. From the energy consumption point of view, it is better to remove larger chips from the surface rather than grinding the rock into dust that has a high specific surface area (total surface area of a material per unit of mass). The volume removed outside the button contact area, especially in between the buttons, is a function of the impact speed. It has been previously [18] reported that the lower striker speeds of $10 \mathrm{~m} / \mathrm{s}$ and $16 \mathrm{~m} / \mathrm{s}$ induce almost no material removal between the buttons for intact Kuru gray granite. However, increasing the striker speed up to $22 \mathrm{~m} / \mathrm{s}$ causes the material to chip off between the buttons in $50 \%$ of the tests. In this study, the striker speed of $35 \mathrm{~m} / \mathrm{s}$ caused material between the indenters to chip off even from the non-heat shocked samples. However, based on the results presented here it is evident that also the pre-existing damage has an effect on the side chipping and material removal from between the buttons. Larger craters are formed also in the center part of the drill bit at higher heat shock damages. Based on preliminary X-Ray CT analysis on the heat shocked rock samples, most of the damage actually occurs very near the sample surface. Based on the micro-CT scans, the heat shock effected layer is only 50-100 micrometers deep, and any damage extending deeper than this is not resolvable with the micro-CT. Therefore, it can be expected that the side chipping is strongly affected by the damage within this layer.

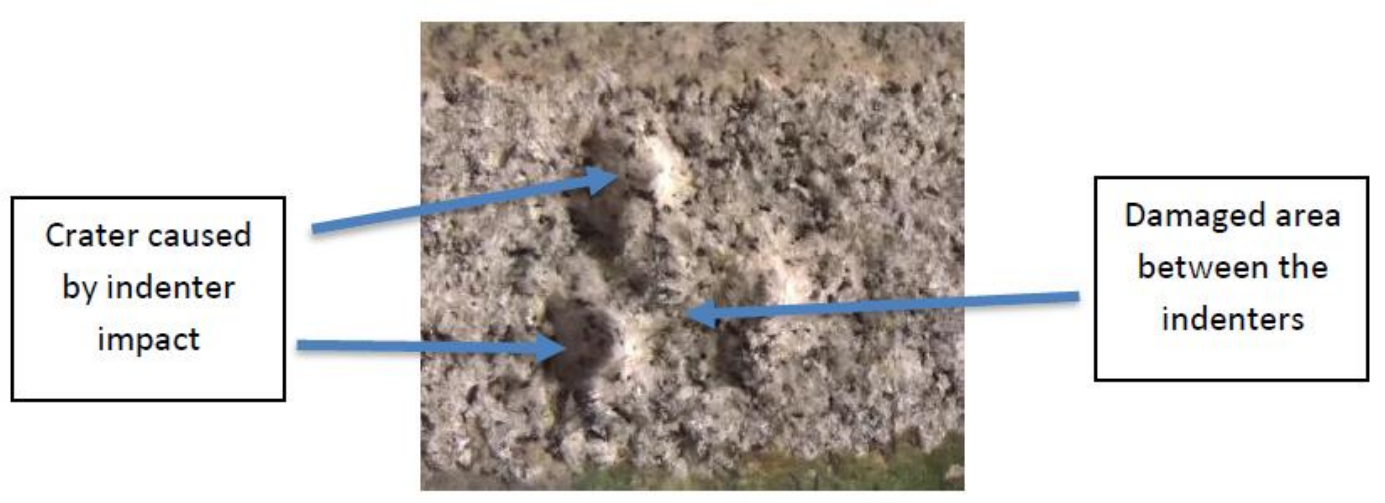

Figure 7. Damaged area on a 6-second heat shocked sample. 

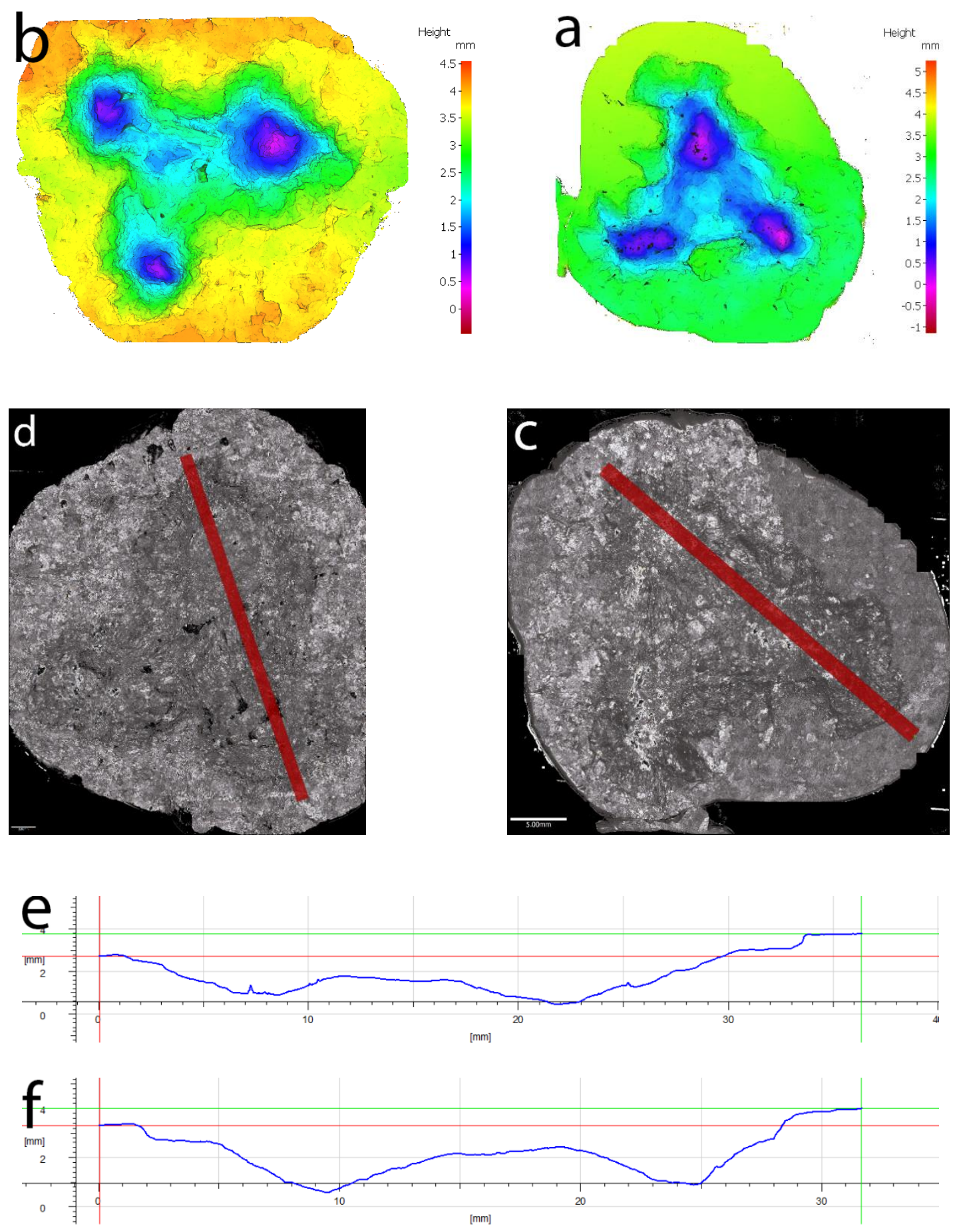

Figure 8. 3D profilometry images of the crater formed during an indentation on a a) 3 second heat shocked surface, perpendicular view of the mapped image, b) 4 second heat shocked surface, perpendicular view of the mapped image, c) 3 second heat shocked surface, perpendicular view of the raw image with the profile line, d) 4 second heat shocked surface, perpendicular view of the raw image with the profile line, e) height profile of the crater for a 3 second heat shock surface, and f) height profile of the crater for a 4 second heat shock surface. 
As it was mentioned before, the triple-button indentation tests provide the opportunity to study the in-situ drilling in a simpler condition and the laboratory condition allows more careful evaluation of the results. Usually the main interest in the drilling process is the overall penetration rate. However, characterization of rock properties and bit-rock interaction forces would be provide valuable insight for drilling and mining applications. Based on this work, the bit-rock interaction forces are quite insensitive to small changes in the rock strength, and the effects of the pre-existing damage and rock strength are more clearly seen in the removed volume and especially in the side chipping and material removal from between the buttons. However, this is only a preliminary conclusion, and its verification will require a more careful examination of the effects of heat shocks on the rock structure using, for example, X-Ray CT scans and electron microscopy. Future work will also include extensive numerical studies, but at the moment they are beyond the scope of this paper.

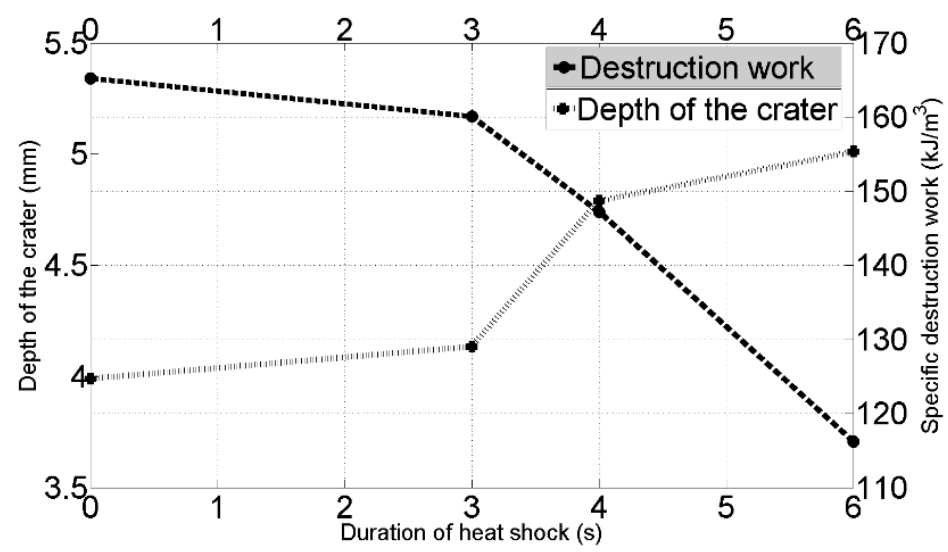

Figure 9. Specific destruction work and depth of the crater as a function of the duration of the heat shock for the triple-button indentation tests.

\section{Concluding remarks}

- This works presents a procedure to alter the rock structure using heat shocks and to study the effect of this change on the mechanical behavior of rock under dynamic loading conditions.

- Based on the results obtained in this work, we believe that the presented procedure can provide useful information also for modeling and simulation purposes.

- At the high impact velocities used in this work, the force vs. displacement curves do not resemble typical experimental bit-rock interaction curves, where elastic recovery is usually observed. However, it has been shown that the behavior of the rock and the bit-rock interaction change at higher speeds, where elastic recovery vanishes as the material is shattered into dust in front of the indenters.

- The force-displacement curves obtained from single-button indentation tests have two maxima. Most likely the second maximum is due to the further penetration of the indenter after crushing the rock surface. This further penetration compacts the dust and powder under the indenter and causes the appearance of the second maximum in the curves. 
- The second maximum is not observed in the triple-button tests. The reason for this can be that the amount of powder and dust is considerably less since the size of the indenters in these tests is different from the single-button tests. In addition, also the material between the indenters is removed, providing enough room for the dust and powder to escape.

- Even though the force-displacement curves provide useful information about the rate of penetration inside the rock, they do not correlate well with the mechanical properties of the rock nor describe the size of the craters and extent of material removal. Therefore, optical profilometry was used to measure the volumes of the craters. The profilometry results indicate an increase in the size of the craters as the duration of the heat shock increases.

- The mechanical energy and the volume of the craters were used to calculate the destruction work. The destruction work decreases as the duration of the heat shock increases. However, in the single-button tests, after a certain duration of the heat shock, the decrease in the destruction work becomes less pronounced.

In triple-button tests, the continuous decrease of the destruction work can be explain by increasing side chipping and material removal between the indenters with increasing thermal shock damage.

\section{Acknowledgment}

This study was supported by Suomen Luonnonvarain Tutkimussäätiö Foundation under grant numbers 1768/14, 1779/15 and 1789/16 and Finland Cultural Foundation.

\section{References}

[1] Ajibose, O., Wiercigroch, M., \& Akisanya, A., 2015. Experimental studies of the resultant contact forces in drillbit-rock interaction. International Journal of Mechanical Sciences, 91, 3-11. https://doi.org/10.1016/j.ijmecsci.2014.10.007

[2] Apostol, M., 2007. Strain rate and Temperature Dependence of the Compression Behavior of FCC and BCC Metals. Tampere: Tampere University of Technology.

[3] Cunningham, R., \& Eenink, J., 1959. Laboratory Study of Effect of Overburden, Formation and Mud Column Pressures on Drilling Rate of Permeable Formations. Society of Petroleum Engineers.

[4] Bauer, S., \& Johnson, B., 1979. Effects of slow uniform heating on the physical properties of westrly and charcoal granite, $20^{\text {th }}$ US symposium on rock mechanics. Austin.

[5] Dwivedi, R., Goel, R., Prasad, V., \& Sinha, A., 2008. Thermo-mechanical properties of Indian and other granites. International journal of rock mechanics and mining sciences, 45(3), 81-99. https://doi.org/10.1016/j.ijrmms.2007.05.008

[6] Fourmeau, M., Gomon, D., Vacher, R., Hokka, M., kane, A., \& Kuokkala, V., 2014. Application of DIC technique for studies of Kuru granite rock under static and dynamic loading. Procedia Materials science, 3 691-697.

https://doi.org/10.1016/j.mspro.2014.06.114 
[7] Gorham, D. A., \& Wu, X., 1997. An Empirical Method of Dispersion Correction in the Compressive Hopkinson Bar Test. Le Journal de Physique, 7(C3), 223-228. https://doi.org/10.1051/jp4:1997340

[8] Han, G., Bruno, M., \& Grant, T., 2006. Lab investigations of percussion drilling: from single impact to full scale fluid hammer. The 41st U.S. Symposium on Rock Mechanics (USRMS). Golden.

[9] Langitan, F., \& Lawn, B., 1970. Effect of a Reactive Environment on the Hertzian Strength of Brittle Solids. Journal of Applied Physics, 41(8), 3357-3365. https://doi.org/10.1063/1.1659425

[10] Lindqvist, P., \& Hai-Hui, L., 1983. Behaviour of the crushed zone in rock indentation. Rock Mechanics and Rock Engineering, 16(3), 199-207. https://doi.org/10.1007/BF01033280

[11] Liu, H., Kou, S., Lindqvist, P., \& Tang, C., 2002. Numerical simulation of the rock fragmentation process induced by indenters. International Journal of Rock Mechanics and Mining Sciences, 39(4), 491-505. https://doi.org/10.1016/S13651609(02)00043-6

[12] Liu, S., \& Xu, J., 2014 Mechanical properties of Qinling biotite granite after high temperature treatment. International journal of rock mechanics and mining sciences, 71, 188-193. https://doi.org/10.1016/j.ijrmms.2014.07.008

[13] Mahanta, B., Singh, T., \& Ranjoth. P., 2016. Influence of thermal treatment on mode I fracture toughness of certain Indian rocks. Engineering Geology, 210, 103114. https://doi.org/10.1016/j.enggeo.2016.06.008

[14] Mardoukhi, A., Hokka, M., \& Kuokkala, V., 2017. A numerical and experimental study on the tensile behavior of plasma shocked granite under dynamic loading. Rakenteiden Mekaniikka, 50(2), 41-62. https://doi.org/10.23998/rm.65301

[15] Mardoukhi, A., Mardoukhi, Y., Hokka, M., \& Kuokkala, V., 2017. Effects of heat shock on the dynamic tensile behavior of granitic rocks. Rock mechanics and rock engineering 50(5), 1171-1182. https://doi.org/10.1007/s00603-017-1168-4

[16] Maurer, W., \& Rinhart, J., 1960. Impact crater fromation in rock. Journal of applied physics, 31(7), 1247-1252. https://doi.org/10.1063/1.1735814

[17] Saksala, T., 2016. Modelling of Dynamic Rock Fracture Process with a RateDependent Combined Continuum Damage-Embedded Discontinuity Model Incorporating Microstructure. Rock Mechanics and Rock Engineering, 49(10), 3947-3962. https://doi.org/10.1007/s00603-016-0994-0

[18] Saksala, T., Gomon, D., Hokka, M., \& Kuokkala, V., 2014. Numerical and experimental study of percussive drilling with a triple-button bit on Kuru granite. International Journal of Impact Engineering, 72, 56-66. https://doi.org/10.1016/j.ijimpeng.2014.05.006

[19] Sirdesai, N., Singh, T., Ranjith, T., \& Singh, R., 2016. Effects of varied durations of thermal treatment on the tensile strength of Red sandstone. Rock mechanics and rock engineering, 50(1), 205-213. https://doi.org/10.1007/s0060

[20] Thuro, K., \& Spaun, G., 1996. Introducing the 'destruction work' as a new rock property of toughness. Prediction and performance in rock mechanics and rock engineering. Turin. 
[21] Wang, S., Sloan, S., Liu, H., \& Tang, C., 2011. Numerical simulation of the rock fragmentation process induced by two drill bits subjected to static and dynamic (impact) loading. Rock mechanics and rock engineering, 44(3), 317-332. https://doi.org/10.1007/s00603-010-0123-4

[22] Wei, R., \& Zang, S., 2006. Effects of Temperature and Strain Rate on Fracture Strength of Rocks and Their Influence on Rheological Structure of the Lithosphere. Chinese journal of geophysics, 49(6), 1576-1584. https://doi.org/10.1002/cjg2.985

Ahmad Mardoukhi, Mikko Hokka, Veli-Tapani Kuokkala

Tampere University of Technology

Laboratory of Material Science

POB 589, FI-33101, Tampere

Finland 